JPE $10-2-6$

\title{
Current-Type Nine-Switch Inverters
}

\author{
Seyed Mohammad Dehghan*, Mustafa Mohamadian ${ }^{\dagger}$, and Ali Yazdian* \\ $\dagger^{\dagger *}$ Faculty of Electrical \& Computer Engineering, Tarbiat Modares University, Tehran, Iran
}

\begin{abstract}
In this paper two dual output current-type inverters are proposed. These inverters have been called a current source nineswitch inverter and a current-type z-source nine-switch inverter by the authors. The proposed inverters have two independent current source outputs. Compared to two independent current source inverters, the proposed converters are implemented with fewer semiconductor switches. Space vector modulation (SVM) is proposed for these converters. Simulation results show the validity and performance of the proposed inverters.
\end{abstract}

Key Words: Current Source Inverter, Nine-Switch Inverter, Multi-output inverter, Space vector modulation, Z-Source Inverter

\section{INTRODUCTION}

Current source inverters (CSIs) are used in many high and medium power industrial applications [1], [2]. An AC/AC conversion system based on a CSI is shown in Fig. 1. The CSI has the advantage of indirect output short-circuit protection. In addition, it has a low output harmonic because of its output capacitors.

In many industrial applications, there is a need to power two AC loads at the same time. The conventional method of controlling two AC loads is to use two separate inverters. This method increases both the cost and volume. In [3], a nine-switch inverter (NSI) was presented for this purpose (Fig. 2). This inverter was used as an AC/AC converter in [4], [5] where two back to back inverters were used conventionally. The nine-switch inverter has three less switches than dual inverters. While the inverter in [3] is a voltage source inverter (VSI), this paper presents a current source inverter with two AC outputs (Fig. 3). The proposed inverter is based on a voltage source nine-switch inverter (VS-NSI). In addition, a space vector modulation (SVM) algorithm has been presented for the proposed inverter. The SVM is based on conventional CSI [6], [7] and nine-switch voltage-source inverter [8] space vector modulations.

The input DC current of the proposed inverter is shared between two outputs. Consequently the maximum output currents for the proposed inverter are less than the single output of a conventional CSI. To remedy this limitation, a current-type z-source nine-switch inverter (CTZS-NSI) is also proposed in this paper (Fig. 4). This converter is composed of a current-source nine-switch inverter and a current-type zsource network. The current-type z-source network acts as a current DC/DC boost converter. The z-source network was

\footnotetext{
Manuscript received Sep. 12, 2009; revised Jan. 3, 2010

$\dagger$ Corresponding Author: mohamadian@modares.ac.ir

Tel: +98-21-82884344, Fax: +98-21-82884325, Tarbiat Modares Univ.

* Faculty of Electrical \& Computer Eng., Tarbiat Modares University, Iran
}

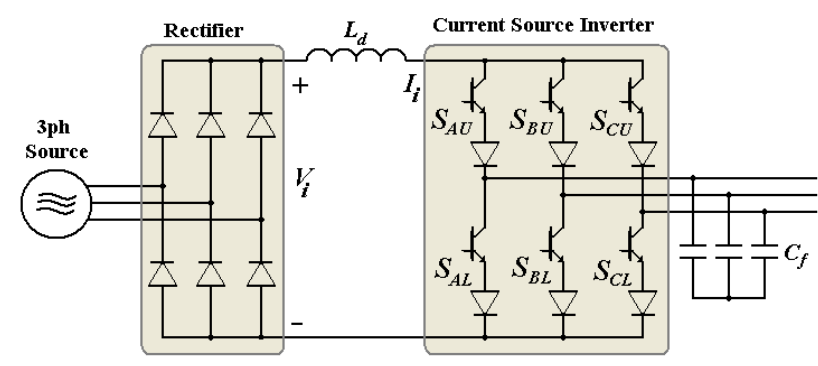

Fig. 1. AC/AC conversion system based on CSI.

proposed as a voltage boost converter in [9], for the first time. Then a current-type z-source network was proposed in [10], as the front stage of a single output CSI. Single output $\mathrm{z}$ source CSIs are developed and analyzed in [11] and [12]. A modified SVM has been proposed for the nine-switch z-source current-type inverter in this paper.

Section II of this paper introduces a current source nineswitch inverter. A SVM method for the CS-NSI is proposed in section III. Section IV presents a current-type z-source nineswitch inverter. In section $\mathrm{V}$, the proposed converters with front-end rectifiers are discussed. Finally, simulation results are presented, to verify the performance of the proposed converter.

\section{Current Source Nine-Switch Inverter}

A conventional CSI (Fig. 1) has nine switching vectors. Six active vectors and three zero vectors. Table I shows the ON switches in each vector. In all of the vectors an upper switch and a lower switch are ON. In this manner, there is always a path for the input DC current. In the active vectors, the ON switches are from different legs. Thus the input DC current passes through the load. However in the zero vectors, both of the ON switches are from the same leg. It is obvious that the input DC current does not pass across the load in the zero 


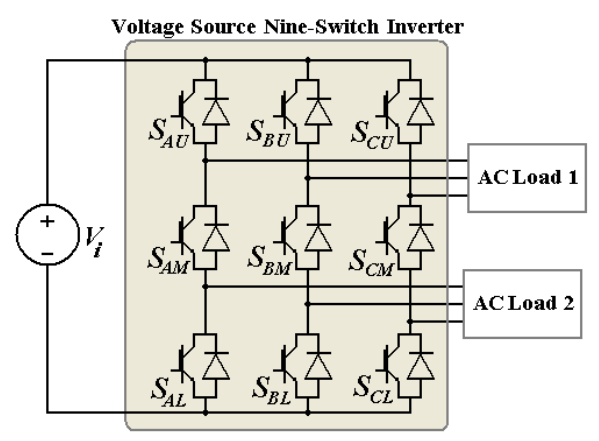

Fig. 2. Voltage source nine-switch inverter (VS-NSI) [3].

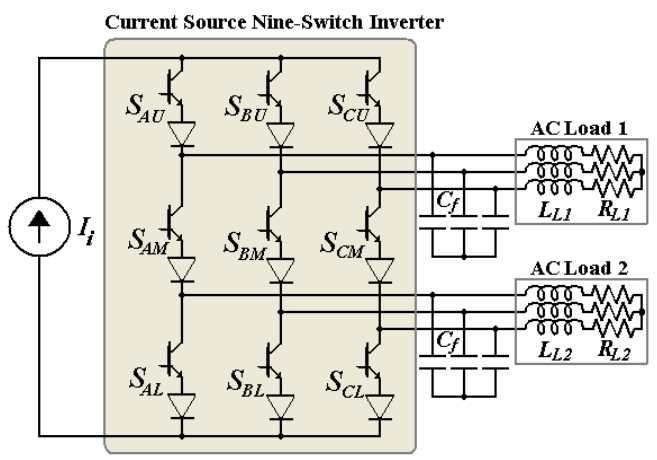

Fig. 3. Proposed current source nine-switch inverter (CS-NSI).

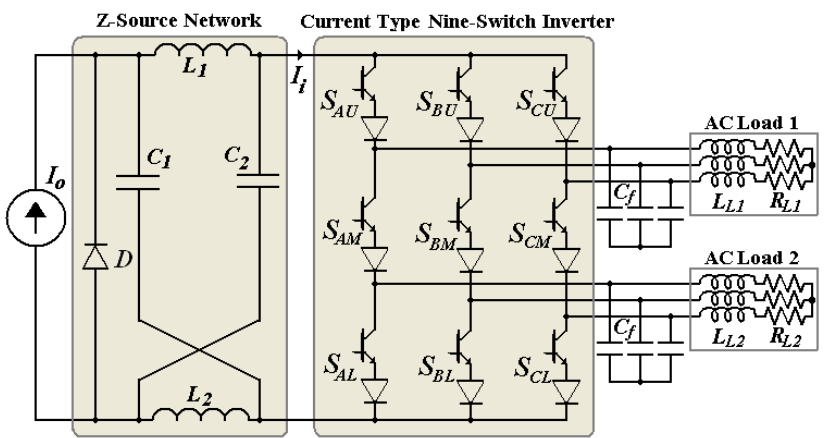

Fig. 4. Proposed current-type z-source nine-switch inverter (CTZS-NSI).

vectors. Thus this current can be used for another load. This is the main idea for the CS-NSI (Fig. 3). The CS-NSI can be considered as two separate conventional CSIs with three common switches. When an inverter is in an active vector, another inverter must be in a zero vector.

For implementation of the above idea, a list of vectors has been created for the CS-NSI, as shown in Table II. The numbers 0 to 5 indicate the state of the switches in each leg. Table III explains the switch states 0 to 5 , where, $J$ is $A, B$ or $C$ and $U, M$ and $L$ are the upper, mid and lower switches. The switching vectors are divided into four groups: upper active vectors, lower active vectors, zero vectors and an open-circuit vector. In the upper active vectors $\left(I_{1}-I_{6}\right)$, the upper output (the upper inverter) is in the active state, and the lower output is in the zero state. There is an inverse logic in the lower active vectors $\left(I_{7}-I_{12}\right)$. In the zero vectors $\left(I_{13}-I_{15}\right)$, both outputs are in the zero state. The open-circuit vector $\left(I_{16}\right)$ is not used for the CS-NSI. Vector $I_{16}$ is used in the CTZS-NSI as described in section IV.

TABLE I

The Switching Vector Of The Conventional Csi (FIg. 1)

\begin{tabular}{|c|c|c|}
\hline Vector & ON Switches & Type \\
\hline 1 & $S_{A U}, S_{C L}$ & \multirow{6}{*}{ Active } \\
\hline 2 & $S_{B U}, S_{C L}$ & \\
\hline 3 & $S_{A L}, S_{B U}$ & \\
\hline 4 & $S_{A L}, S_{C U}$ & \\
\hline 5 & $S_{B L}, S_{C U}$ & \\
\hline 6 & $S_{A U}, S_{B L}$ & \\
\hline 7 & $S_{A U}, S_{A L}$ & \multirow{3}{*}{ Zero } \\
\hline 8 & $S_{B U}, S_{B L}$ & \\
\hline 9 & $S_{C U}, S_{C L}$ & \\
\hline
\end{tabular}

TABLE II

The Switching Vectors Of The Current-Type Nine-Switch INVERTERS (FIG. 3)

\begin{tabular}{|c|c|c|c|c|}
\hline Vector & Leg A & Leg B & Leg C & Type \\
\hline 1 & 2 & 0 & 1 & \\
2 & 0 & 2 & 1 & \\
3 & 1 & 2 & 0 & Upper Active \\
4 & 1 & 0 & 2 & \\
5 & 0 & 1 & 2 & \\
6 & 2 & 1 & 0 & \\
\hline 7 & 4 & 0 & 3 & \\
8 & 0 & 4 & 3 & \\
9 & 3 & 4 & 0 & Lower Active \\
10 & 3 & 0 & 4 & \\
11 & 0 & 3 & 4 & \\
12 & 4 & 3 & 0 & \\
\hline 13 & 5 & 0 & 0 & \\
14 & 0 & 5 & 0 & Zero \\
15 & 0 & 0 & 5 & \\
\hline 16 & 0 & 0 & 0 & Open-Circuit \\
\hline
\end{tabular}

TABLE III

Vector Switch State In CuRRent-Type Nine-Switch InVERTERS (TABLE II)

\begin{tabular}{|c|c|c|c|}
\hline & $S_{J U}$ & $S_{J M}$ & $S_{J L}$ \\
\hline 0 & OFF & OFF & OFF \\
\hline 1 & OFF & ON & ON \\
\hline 2 & ON & OFF & OFF \\
\hline 3 & OFF & OFF & ON \\
\hline 4 & ON & ON & OFF \\
\hline 5 & ON & ON & ON \\
\hline
\end{tabular}

\section{Svm Method For A Current-Source NINE-SWITCH INVERTER}

Fig. 5 shows a proposed sequence of switching vectors for implementing the SVM method for a current source nine-switch inverter. The sequence includes the upper active vectors, the lower active vectors and the zero vectors in each switching cycle. 


\begin{tabular}{|c|c|c|c|c|c|c|c|c|c|c|c|c|}
\hline$I_{\mathrm{Z}}$ & $I_{\mathrm{AU}}$ & $I_{\mathrm{AU}}$ & $I_{\mathrm{Z}}$ & $I_{\mathrm{AL}}$ & $I_{\mathrm{AL}}$ & $I_{\mathrm{Z}}$ & $I_{\mathrm{AU}}$ & $I_{\mathrm{AU}}$ & $I_{\mathrm{Z}}$ & $I_{\mathrm{AL}}$ & $I_{\mathrm{AL}}$ & $I_{\mathrm{Z}}$ \\
\hline \hline$\frac{\mathbf{T}_{0}}{4}$ & $\mathbf{T}_{1}$ & $\mathbf{T}_{2}$ & $\frac{\mathbf{T}_{0}}{2}$ & $\mathbf{T}_{\mathbf{3}}$ & $\mathbf{T}_{\mathbf{4}}$ & $\frac{\mathbf{T}_{\mathbf{0}}}{2}$ & $\mathbf{T}_{2}$ & $\mathbf{T}_{\mathbf{1}}$ & $\frac{\mathbf{T}_{\mathbf{0}}}{\mathbf{2}}$ & $\mathbf{T}_{\mathbf{4}}$ & $\mathbf{T}_{\mathbf{3}}$ & $\frac{\mathbf{T}_{\mathbf{0}}}{\mathbf{4}}$ \\
\hline
\end{tabular}

Fig. 5. The switching vector sequence of SVM for CS-NSI.

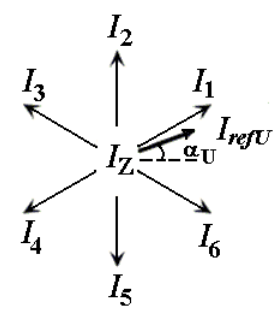

(a)

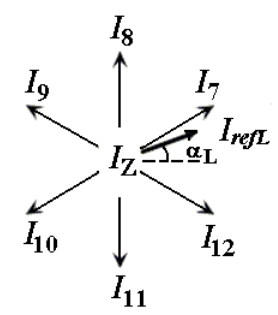

(b)
Fig. 6. Space vector diagrams for CS-NSI: a) Upper output, b) Lower output.

To determine the correct active vectors, two space vector diagrams are proposed as shown in Fig. 6. Diagrams (a) and (b) are used to determine the upper and lower active vectors respectively. The SVM active vectors are determined with regard to the location of the upper reference signal $\left(\bar{I}_{\text {refU }}\right)$ in diagram (a) and the lower reference signal $\left(\bar{I}_{\text {refL }}\right)$ in diagram (b). The reference signals for the upper and lower outputs are defined as:

$$
\begin{aligned}
& \bar{I}_{r e f U}=I_{r e f U} \angle \alpha_{U} \\
& \bar{I}_{r e f U}=I_{r e f U} \angle \alpha_{U}
\end{aligned}
$$

where

$$
\begin{aligned}
& \alpha_{U}=2 \pi f_{U} t+\phi_{U} \\
& \alpha_{L}=2 \pi f_{L} t+\phi_{L}
\end{aligned}
$$

where, $f_{U}$ and $f_{L}$ are the frequencies, and $\phi_{U}$ and $\phi_{U}$ are the phases. All of the zero vectors $I_{13}, I_{14}$ and $I_{15}$ can be used for the zero states. The switching time intervals of the vectors are calculated as:

$$
\begin{aligned}
& T_{1}=\frac{\sqrt{3}}{2} m_{U} T \sin \left(\frac{\pi}{3}-\alpha_{U}\right) \\
& T_{2}=\frac{\sqrt{3}}{2} m_{U} T \sin \left(\alpha_{U}\right) \\
& T_{3}=\frac{\sqrt{3}}{2} m_{L} T \sin \left(\frac{\pi}{3}-\alpha_{L}\right) \\
& T_{4}=\frac{\sqrt{3}}{2} m_{L} T \sin \left(\alpha_{L}\right) \\
& T_{o}=T-T_{1}-T_{2}-T_{3}-T_{4}
\end{aligned}
$$

where, $T_{1}$ and $T_{2}$ are the time intervals of the upper active vectors, $T_{3}$ and $T_{4}$ are the time intervals of the lower active vectors, $T_{o}$ is the time interval of the zero vectors and $T$ is the switching period. $m_{U}$ and $m_{L}$ are the upper and lower modulation indices respectively and they are defined by:

$$
\begin{aligned}
& m_{U}=\frac{2 \sqrt{2}}{\sqrt{3}} \frac{I_{\text {refU }}}{I_{i}} \\
& m_{L}=\frac{2 \sqrt{2}}{\sqrt{3}} \frac{I_{\text {refL }}}{I_{i}} .
\end{aligned}
$$

\begin{tabular}{|c|c|c|c|c|c|c|c|c|c|c|c|c|c|c|}
\hline$I_{\mathrm{Z}}$ & $I_{\mathrm{OC}}$ & $I_{\mathrm{AU}}$ & $I_{\mathrm{AU}}$ & $I_{\mathrm{AL}}$ & $I_{\mathrm{AL}}$ & $I_{\mathrm{OC}}$ & $I_{\mathrm{Z}}$ & $I_{\mathrm{OC}}$ & $I_{\mathrm{AU}}$ & $I_{\mathrm{AU}}$ & $I_{\mathrm{AL}}$ & $I_{\mathrm{AL}}$ & $I_{\mathrm{OC}}$ & $I_{\mathrm{Z}}$ \\
\hline \hline & $\mathbf{T}_{\mathbf{0}} / \mathbf{2}$ & $\mathbf{T}_{\mathbf{2}}$ & $\mathrm{T}_{\mathbf{1}}$ & $\mathbf{T}_{\mathbf{4}}$ & $\mathbf{T}_{\mathbf{3}}$ & $\mathbf{T}_{\mathbf{0}} / \mathbf{2}$ & & $\mathbf{T}_{\mathbf{0}}$ & $\mathbf{T}_{\mathbf{0}} / 2$ & $\mathbf{T}_{\mathbf{1}}$ & $\mathbf{T}_{\mathbf{2}}$ & $\mathbf{T}_{\mathbf{3}}$ & $\mathbf{T}_{\mathbf{4}}$ & $\mathbf{T}_{\mathbf{0 c}} / \mathbf{2}$ \\
\hline $\mathbf{T}_{\mathbf{0}} / \mathbf{2}$ & $\mathbf{T}_{\mathbf{0}} / \mathbf{2}$ \\
\hline
\end{tabular}

Fig. 7. Space vector modulation (SVM) of CTZS-NSI.

The sum of the active vector time intervals must be less than or equal to $T$. Thus the following constraint must be satisfied:

$$
\left(m_{U}+m_{L}\right) \leq \frac{1}{\sqrt{3}}
$$

\section{Current-Type Z-Source Nine-Switch InVErter}

Considering (12), it is obvious that the output currents from a nine-switch inverter are lower than those from a conventional CSI of the same power. As a solution, a currenttype z-source nine-switch inverter (CTZS-NSI) is proposed. A current-type z-source inverter was presented in [10] and [11], previously. However, we have modified the current type ZSI to accommodate two loads at the same time by using a nineswitch topology.

Fig. 4 shows the proposed CTZS-NSI. This converter is composed of a current-type z-source network and a CS-NSI. The current-type z-source network includes two inductors $\left(L_{1}\right.$ $\left.\& L_{2}\right)$, two capacitors $\left(C_{1} \& C_{2}\right)$ and one diode $(D)$, as shown in Fig. 4. If a bidirectional power flow is required, diode $D$ can be replaced by a voltage-bidirectional two-quadrant switch (such as an IGBT in series with a diode).

The current-type z-source network causes the input DC current of a CS-NSI $\left(I_{i}\right)$, to be larger than the DC terminal current $\left(I_{o}\right)$. Therefore the z-source network operates as a current boost converter. This DC/DC converter has two operation modes. In the first mode, the output of the converter should be open-circuit. Consequently the diode $D$ turns ON (If a switch is used instead of a diode $D$, it should be forced ON). This mode is known as the open-circuit mode. The open-circuit mode can be implemented by turning OFF all the switches in the CS-NSI. Vector $I_{16}$ from Table II can create an open-circuit mode. The second mode is known as the non-open-circuit mode. In this mode, there is a path for the output current of the z-source converter and the diode $D$ turns OFF. This mode occurs if the CS-NSI is in one of the vector $I_{1}-I_{15}$ states. As described in [10], the relationship between the output current of the z-source network $\left(I_{i}\right)$ and the input DC current $\left(I_{o}\right)$ is defined by:

$$
I_{i}=B I_{o}
$$

where, $B$ is known as the boost factor and is given by following equation:

$$
B=\frac{1}{1-2\left(T_{O C} / T\right)}
$$

where $T_{O C}$ is time interval of the open-circuit vector $\left(I_{16}\right)$.

The proposed SVM for a CS-NSI can be modified for a CTZS-NSI (Fig. 7). As shown in Fig. 7, the two open-circuit vectors $\left(I_{O C}\right)$ are inserted at both sides of the zero vectors $\left(I_{Z}\right)$. The active vectors are determined via the diagrams in Fig. 6. $T_{1}, T_{2}, T_{3}, T_{4}$ and $T_{o}$ are calculated by (5-9) and $T_{O C}$ is determined by (14). 


\section{Current-Type Nine-Switch Inverters With A FRONT-END RECTIFIER}

A voltage source such as a front end rectifier (Fig. 1) in series with an inductance is used as a current source. In this case, the CSI acts as a voltage boost converter [10]:

$$
v_{a c}=\frac{4}{3 \sqrt{3}} \frac{V_{i}}{m \cos \varphi}
$$

where $V_{i}$ is the DC source voltage, $v_{a c}$ is the output peak phase voltage and $\cos \varphi$ is the power factor of the load. According to the above equation, there is a voltage limitation for the output such that:

$$
v_{a c-\min }=\frac{2}{3} \frac{V_{i}}{\cos \varphi} .
$$

To remedy this problem a variable voltage source such as a controlled rectifier is used for a low voltage application.

Now, we discuss the proposed converter with a front-end rectifier. In the case of the proposed CS-NSI, we have:

$$
\begin{aligned}
& i_{a c U}=\frac{\sqrt{3}}{2} m_{U} I_{i} \\
& i_{a c L}=\frac{\sqrt{3}}{2} m_{L} I_{i}
\end{aligned}
$$

where $i_{a c U}$ and $i_{a c U}$ are the peak current of the upper and lower outputs, respectively. Since the input and output powers of the converter are equal, it can be written:

$$
\begin{aligned}
P_{\text {in }} & =P_{\text {out }} \\
V_{i} I_{i} & =\frac{3}{2}\left(i_{a c U} v_{a c U} \cos \varphi_{U}+i_{a c L} v_{a c L} \cos \varphi_{L}\right) \\
V_{i} & =\frac{3 \sqrt{3}}{4}\left(m_{U} v_{a c U} \cos \varphi_{U}+m_{L} v_{a c L} \cos \varphi_{L}\right) .
\end{aligned}
$$

On other hand:

$$
\begin{aligned}
& v_{a c U}=z_{\text {LoadU }} i_{a c U} \\
& v_{a c L}=z_{\text {LoadL }} i_{a c L} .
\end{aligned}
$$

Considering (17), (18), (22) and (23), we have:

$$
\frac{v_{a c U}}{v_{a c L}}=\frac{m_{U} z_{\text {LoadU }}}{m_{L} z_{\text {Load } L}} .
$$

According to (21) and (24), the peak phase voltage of the outputs can be calculated by:

$$
\begin{aligned}
& v_{a c U}=\frac{4}{3 \sqrt{3}} \frac{m_{U} z_{\text {LoadU }}}{m_{U}^{2} z_{\text {LoadU }} \cos \varphi_{U}+m_{L}^{2} z_{\text {LoadL }} \cos \varphi_{L}} V_{i} \\
& v_{a c L}=\frac{4}{3 \sqrt{3}} \frac{m_{L} z_{\text {LoadL }}}{m_{U}^{2} z_{\text {LoadU }} \cos \varphi_{U}+m_{L}^{2} z_{\text {LoadL }} \cos \varphi_{L}} V_{i} .
\end{aligned}
$$

As can be seen from the above equations, the output voltage outputs are not independent. However modulation indices can be calculated for desirable output voltages by:

$$
\begin{aligned}
& m_{U}=\frac{4}{3 \sqrt{3}} \frac{1}{\cos \varphi_{U}+\left(\frac{v_{a c L}}{v_{a c U}}\right)^{2}\left(\frac{z_{L o a d U}}{z_{\text {LoadL }}}\right) \cos \varphi_{L}} \frac{V_{i}}{v_{a c U}} \\
& m_{L}=\frac{4}{3 \sqrt{3}} \frac{1}{\left(\frac{v_{a c U}}{v_{a c L}}\right)^{2}\left(\frac{z_{L o a d L}}{z_{\text {LoadU }}}\right) \cos \varphi_{U}+\cos \varphi_{L}} \frac{V_{i}}{v_{a c L}}
\end{aligned}
$$

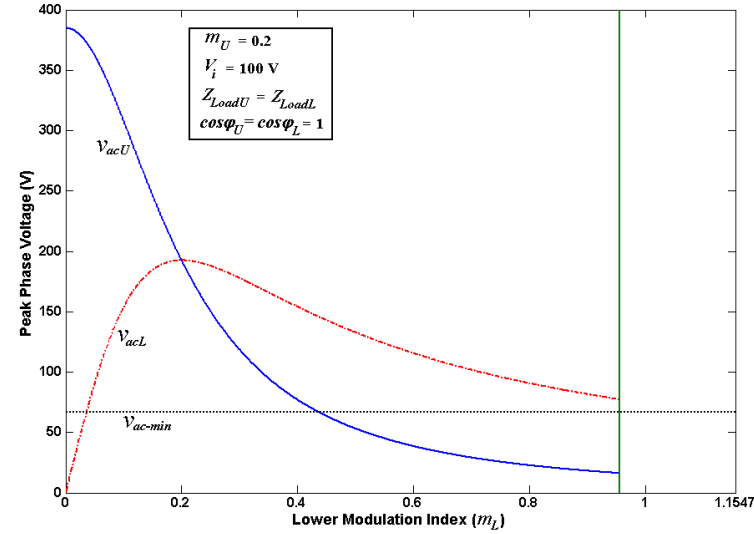

Fig. 8. Typical curve of CS-NSI output voltages for various modulation indices.

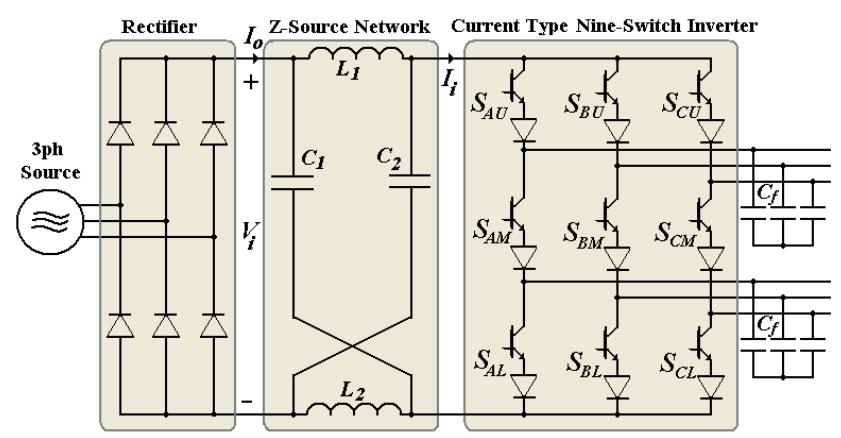

Fig. 9. CTZS-NSI with front-end rectifier.

Unlike a conventional CSI, the proposed CS-NSI can function as a voltage buck-boost convertor. Both outputs of the CS-NSI can be used as a voltage boost converter or one of them can be used as a boost converter while the other is used as a buck converter. However both can not be used as buck converters at the same time. Fig. 8 shows a typical curve for CS-NSI output voltages for various modulation indices. The dotted line is related to the minimum voltage for a conventional CSI in similar conditions.

In the case of a CTZS-NSI, the inductor and diode D (in Fig. 4) can be removed when a front-end rectifier is used (Fig. 9). Equations (20) and (21) can be rewritten for the CTZS-NSI as:

$$
\begin{aligned}
\frac{V_{i} I_{i}}{B} & =\frac{3}{2}\left(i_{a c U} v_{a c U} \cos \varphi_{U}+i_{a c L} v_{a c L} \cos \varphi_{L}\right) \\
\frac{V_{i}}{B} & =\frac{3 \sqrt{3}}{4}\left(m_{U} v_{a c U} \cos \varphi_{U}+m_{L} v_{a c L} \cos \varphi_{L}\right) .
\end{aligned}
$$

Therefore we have,

$$
\begin{aligned}
& v_{a c U}=\frac{4}{3 \sqrt{3}} \frac{m_{U} z_{\text {LoadU }}}{m_{U}^{2} z_{\text {LoadU }} \cos \varphi_{U}+m_{L}^{2} z_{\text {LoadL }} \cos \varphi_{L}} \frac{V_{i}}{B} \\
& v_{a c U}=\frac{4}{3 \sqrt{3}} \frac{m_{L} z_{\text {LoadL }}}{m_{U}^{2} z_{\text {LoadU }} \cos \varphi_{U}+m_{L}^{2} z_{\text {LoadL }} \cos \varphi_{L}} \frac{V_{i}}{B} .
\end{aligned}
$$

In a CTZS-NSI, the low output voltage for both outputs can be generated using $B . B$ can also be used for constant current control of the dc link current. Consequently the output voltages can be controlled independently. 


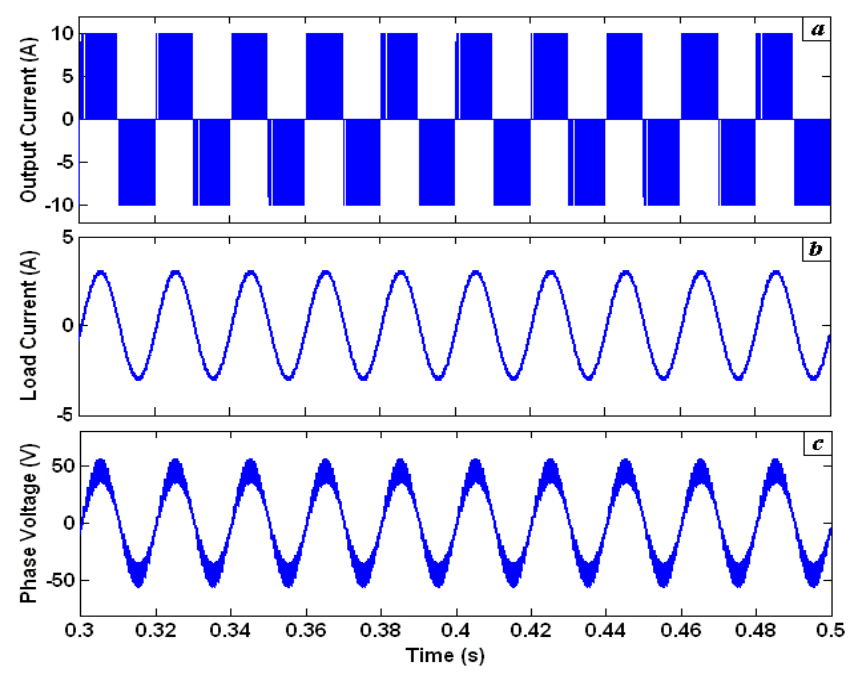

Fig. 10. Upper output of CS-NSI based on ideal source: a) Output current before filter capacitor $C_{f}$. b) Load current. C) Phase voltage.

\section{Simulation Verification}

The simulation results of proposed converters are discussed in this section. This section has three parts: $A$ ) a simulation based on an ideal input current source $B$ ) a simulation based on a front-end rectifier $C$ ) Calculation and comparison of the efficiency and the total harmonic distortion (THD). Similar RL loads are connected to the outputs of the inverters. Table IV shows the simulation parameters.

TABLE IV

PARAMETERS OF SimUlation

\begin{tabular}{|l|l|l|}
\hline Parameter & Sim. A & Sim. B \\
\hline Switching Frequency $\left(f_{S}\right)$ & $2 \mathrm{kHz}$ & $6.3 \mathrm{kHz}$ \\
\hline Reference Upper Output & $I_{\text {refU }}=2 \mathrm{~A}$ & $v_{a c U}=400 \mathrm{~V}$ \\
\hline Reference Lower Output & $I_{r e f L}=3 \mathrm{~A}$ & $v_{a c U}=300 \mathrm{~V}$ \\
\hline Upper Load Frequency $\left(f_{U}\right)$ & $50 \mathrm{~Hz}$ & $25 \mathrm{~Hz}$ \\
\hline Lower Load Frequency $(f L)$ & $10 \mathrm{~Hz}$ & $50 \mathrm{~Hz}$ \\
\hline Filter Capacitor $(C f)$ & $45 \mathrm{uF}$ & $45 \mathrm{uF}$ \\
\hline$R_{L 1} \&$ RL2 (Loads) & $15 \Omega$ & $50 \Omega$ \\
\hline$L_{L 1} \& L_{L 2}($ Loads $)$ & $2 \mathrm{mH}$ & $50 \mathrm{mH}$ \\
\hline C1 \& C2 (Z-Source Net. $)$ & $150 \mu \mathrm{F}$ & $2 \mu \mathrm{F}$ \\
\hline L1 \& L2 (Z-Source Net. $)$ & $40 \mathrm{mH}$ & $15 \mathrm{mH}$ \\
\hline Resistance of L1\& L2 & - & $0.1 \Omega$ \\
\hline DC Link Filter $\left(L_{d}\right)($ Fig. 1$)$ & - & $30 \mathrm{mH}$ \\
\hline Resistance of $L_{d}$ & - & $0.2 \Omega$ \\
\hline
\end{tabular}

\section{A. Ideal input current source}

First, the CS-NSI was simulated with an input ideal DC current source of 10A. The output currents (before the filter capacitor $C_{f}$ ), load currents and phase voltages are shown in Fig. 10 and Fig. 11 for the upper and lower outputs, respectively. It can be seen that load currents are equaled to the reference values in Table IV (2A and 3A). In addition, the signals have the expected frequencies of 50 and $10 \mathrm{~Hz}$.

In the second simulation, a current-type z-source network was added to the CS-NSI. The magnitude of the DC current source is 7A. Considering (14), to boost the input current to

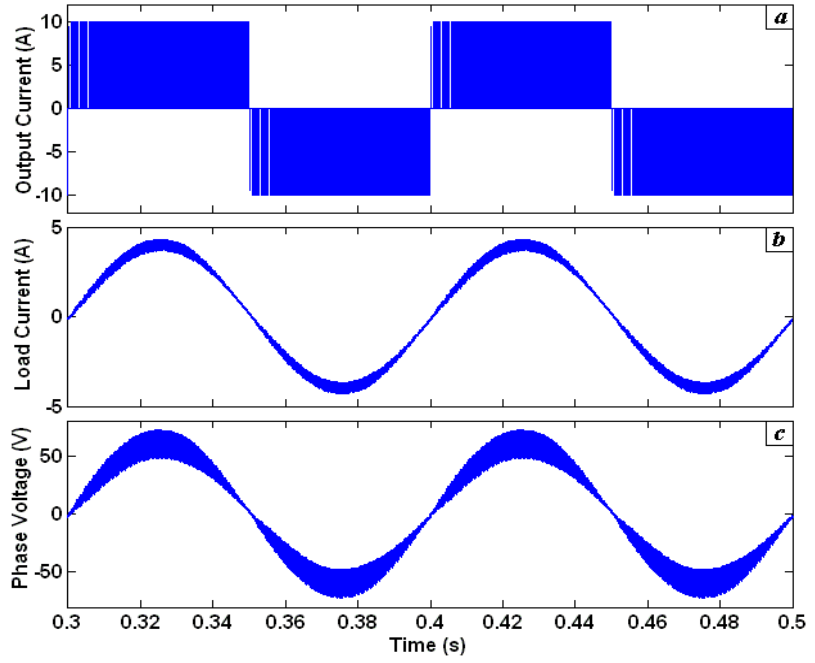

Fig. 11. Lower output of CS-NSI based on ideal source: a) Output current before filter capacitor $C_{f}$. b) Load current. C) Phase voltage.

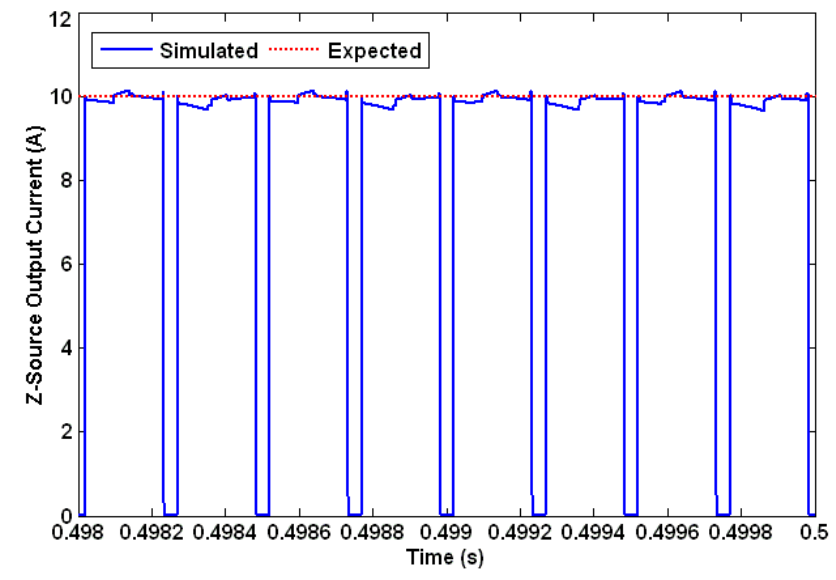

Fig. 12. Z-source output current in CTZS-NSI based on ideal source $\left(I_{i}\right.$ in Fig. 4).

$10 \mathrm{~A}, T_{O C} / T$ was set to 0.15 . The output current of the $\mathrm{z}$ source network $\left(I_{i}\right)$ is shown in Fig. 12. As expected, the $I_{i}$ magnitude changes between $0 \mathrm{~A}$ and 10A. Fig. 13 shows the $\mathrm{z}$-source network inductor current. The current is equal to the expected value of $8.5 \mathrm{~A}$. The inductor current is $0.5\left(I_{o}+I_{i}\right)$, as described in [10]. Fig. 14 and Fig. 15 show the output current, load current and phase voltage of the two outputs.

\section{B. Front-end rectifier}

Now, the ideal input current source is replaced with a frontend rectifier connected to the grid $(380 \mathrm{~V}-60 \mathrm{~Hz})$. The peak phase voltage is used as the reference value $(400 \mathrm{~V}$ and $300 \mathrm{~V}$ for the upper and lower outputs, respectively).

For the CS-NSI, according to these reference values, the modulation indices were calculated by (27) and (28). The grid voltage, $V_{i}$ is considered to be $512 \mathrm{~V}$ in these equations. Fig. 16 and Fig. 17 show the output currents, load currents and phase voltages. It can be seen from the phase voltages that the reference values are generated. Some ripple can be seen in the output currents. This is due to non-ideal current source ripple, as shown in Fig. 18. 


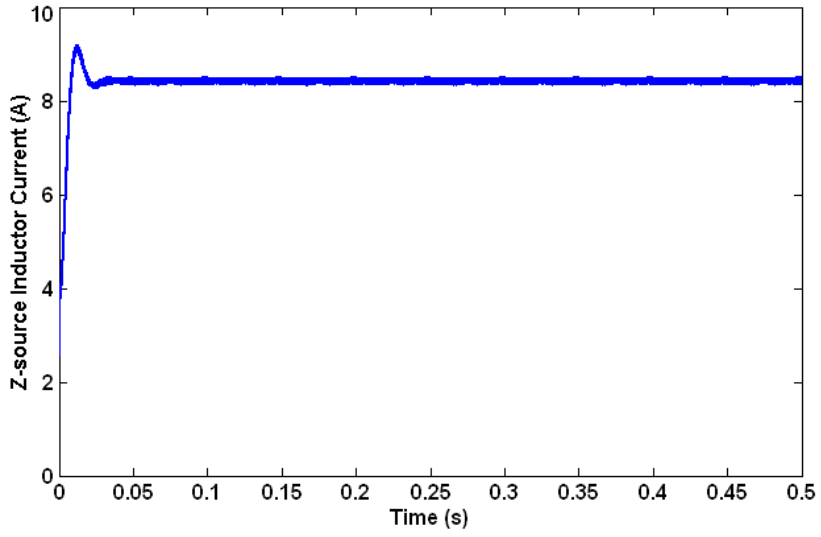

Fig. 13. Z-source inductor current of CTZS-NSI based on ideal source $\left(L_{1}\right.$ current in Fig. 4).

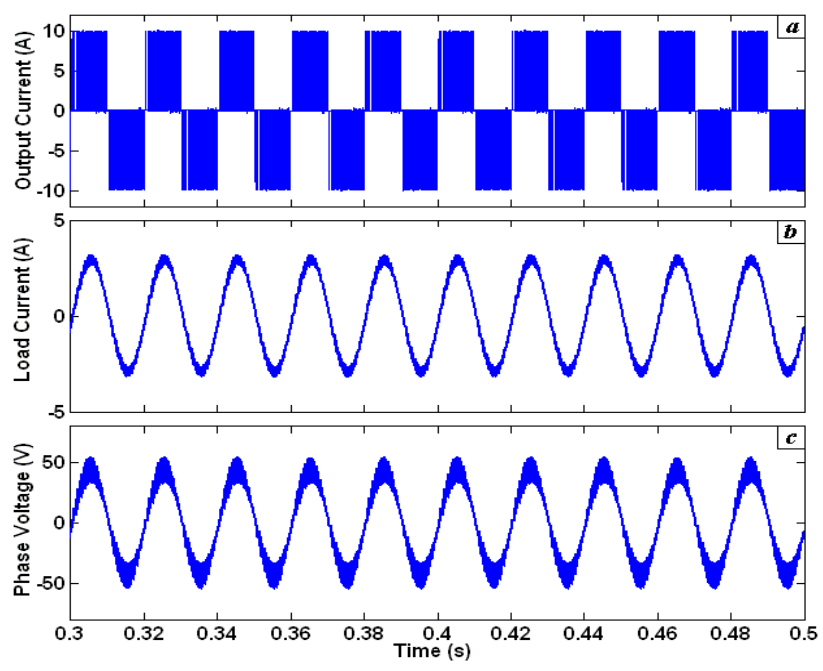

Fig. 14. Upper output of CTZS-NSI based on ideal source: a) Output current before filter capacitor $C_{f}$. b) Load current. C) Phase voltage.

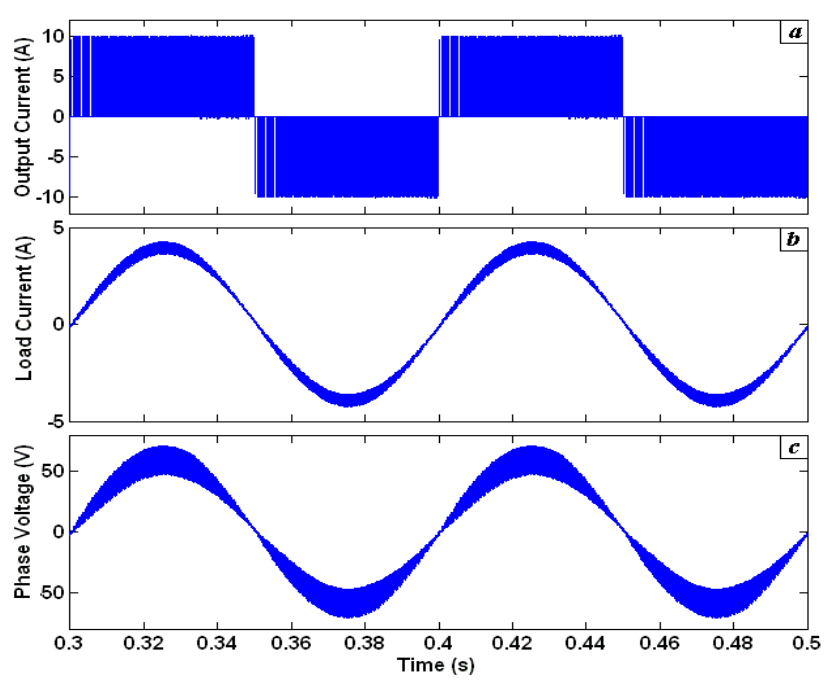

Fig. 15. Lower output of CTZS-NSI based on ideal source: a) Output current before filter capacitor $C_{f}$. b) Load current. C) Phase voltage.

For the CTZS-NSI, the topology shown in Fig. 9 has been simulated. The boost factor $(B)$ was selected as 1.43 . The modulation indices calculated by (27) and (28) were divided

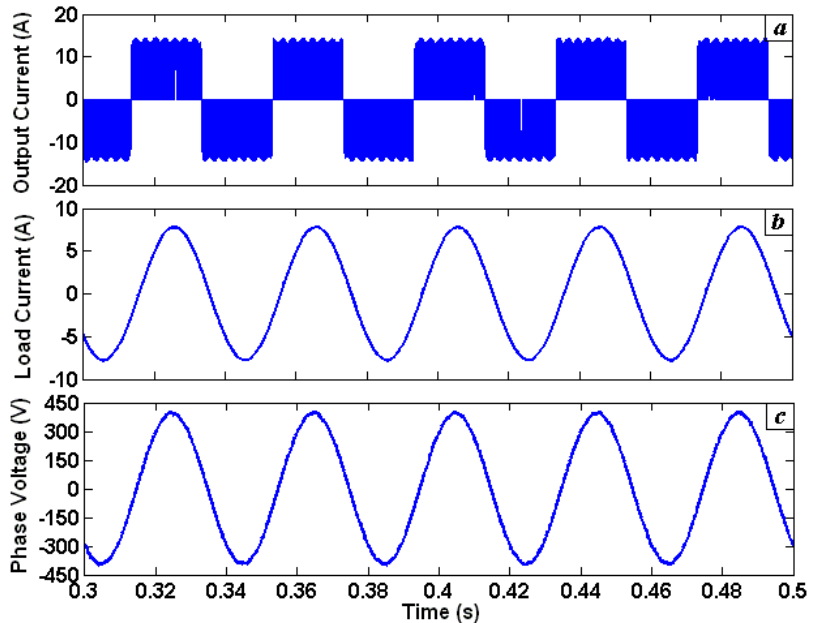

Fig. 16. Upper output of CS-NSI based on front-end rectifier: a) Output current before filter capacitor $C_{f}$. b) Load current. C) Phase voltage.

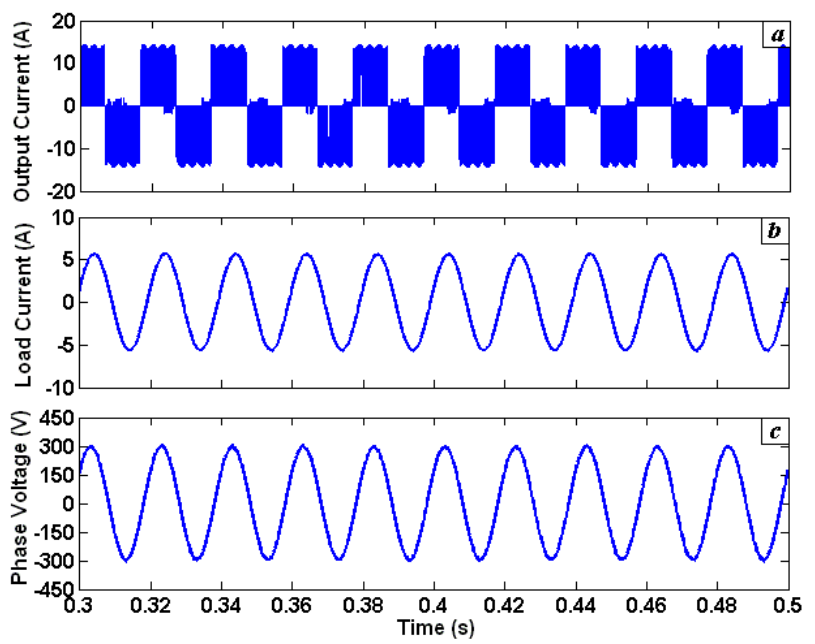

Fig. 17. Lower output of CS-NSI based on front-end rectifier: a) Output current before filter capacitor $C_{f}$. b) Load current. C) Phase voltage.

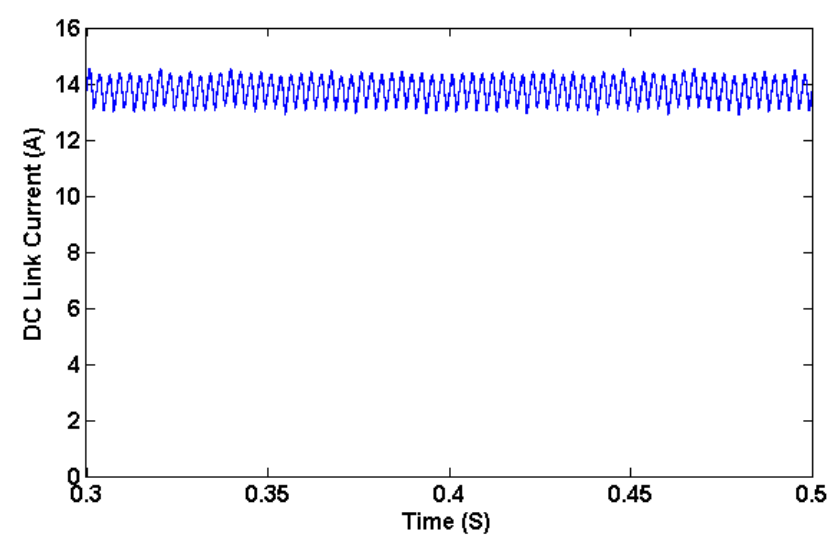

Fig. 18. DC link current of CS-NSI based on front-end rectifier.

by $B$. The output currents, load currents and phase voltages are shown in Fig. 19 and Fig. 20. The output and input currents of the z-source network are shown in Fig. 21. The magnitude of the z-source output current $\left(I_{i}\right)$ changes between $0 \mathrm{~A}$ and $20 \mathrm{~A}$. The magnitude of the $\mathrm{z}$-source output current 


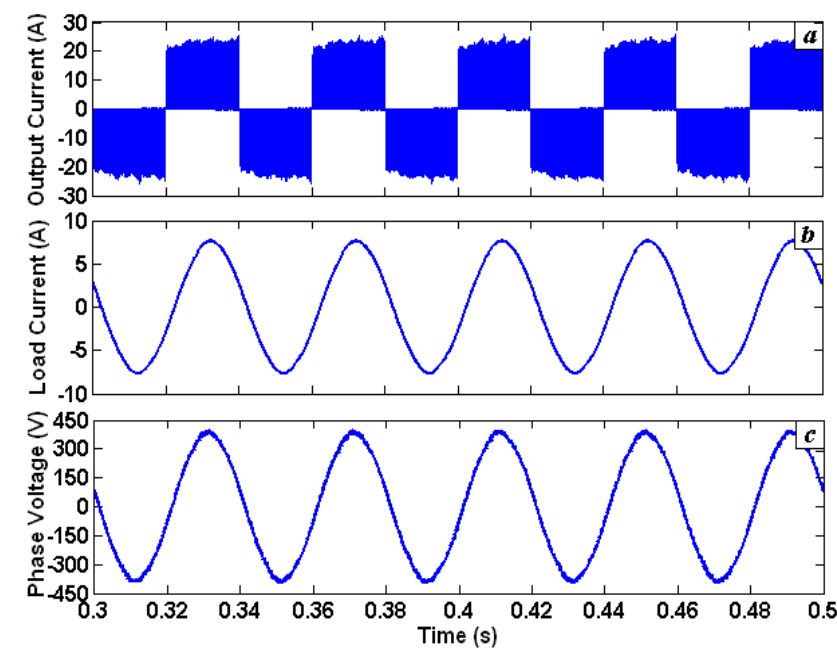

Fig. 19. Upper output of CTZS-NSI based on front-end rectifier: a) Output current before filter capacitor $C_{f}$. b) Load current. C) Phase voltage.

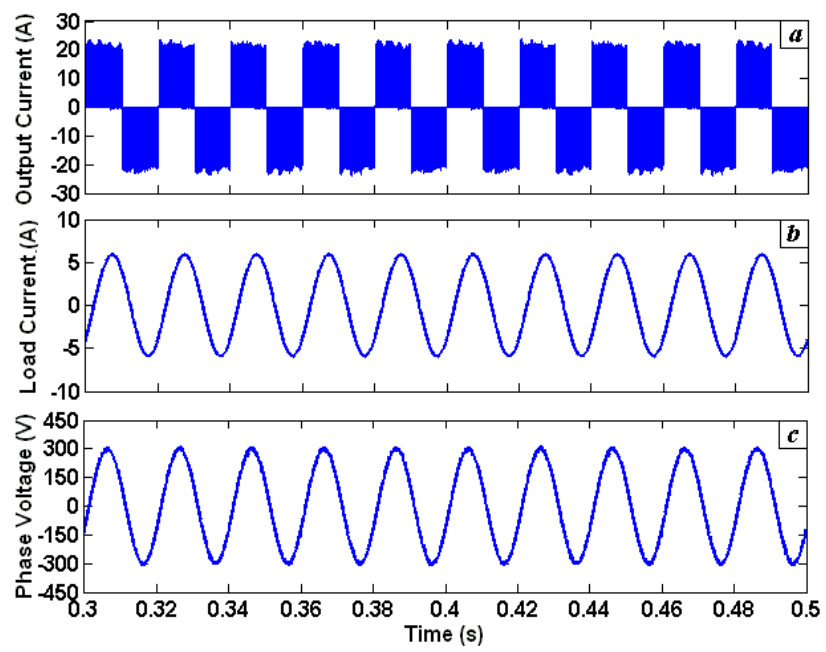

Fig. 20. Lower output of CTZS-NSI based on front-end rectifier: a) Output current before filter capacitor $C_{f}$. b) Load current. C) Phase voltage.

$\left(I_{o}\right)$ changes between 14A and 34A. 14A happens during the non-open circuit vectors and is equal to the DC link current in the pervious simulation (because the consumed power is the same in both simulations). Consequently a value of $20 \mathrm{~A}$ in $I_{i}$ is expectable according to (14). The value of $I_{o}$ as $34 \mathrm{~A}$ is related to the open-circuit vectors and is equal to sum of the $\mathrm{z}$-source inductor currents. The $\mathrm{z}$-source inductor current is shown in Fig. 22 which is equal to the expected value of $17 \mathrm{~A}\left(0.5 I_{o}+0.5 I_{i}\right)$.

\section{Efficiency}

For an efficiency comparison, a CS-NSI with a front-end rectifier is compared with two parallel conventional CSIs with a common front-end rectifier (Fig. 23). The total power loss includes the power losses related to the rectifier, inductor and current source inverters. By using a bridge rectifier module, the dissipation can be calculated versus current from the datasheet. The power loss of the inductor is composed of the core loss and resistive loss. We used Micrometal design software to design the inductor and calculate the power loss [13].

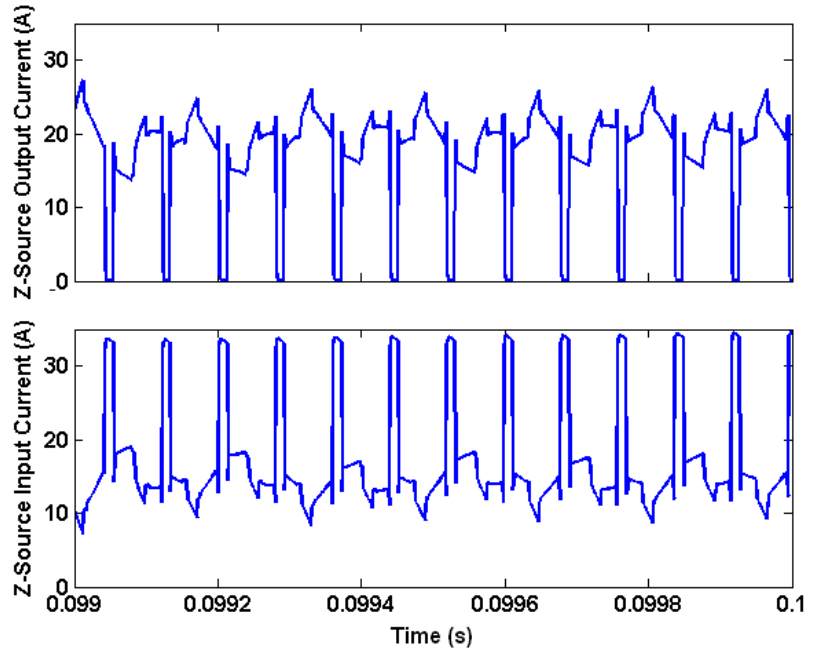

Fig. 21. Output and input currents of z-source network in CTZS-NSI based on front-end rectifier ( $I_{i}$ and $I_{O}$ in Fig. 9).

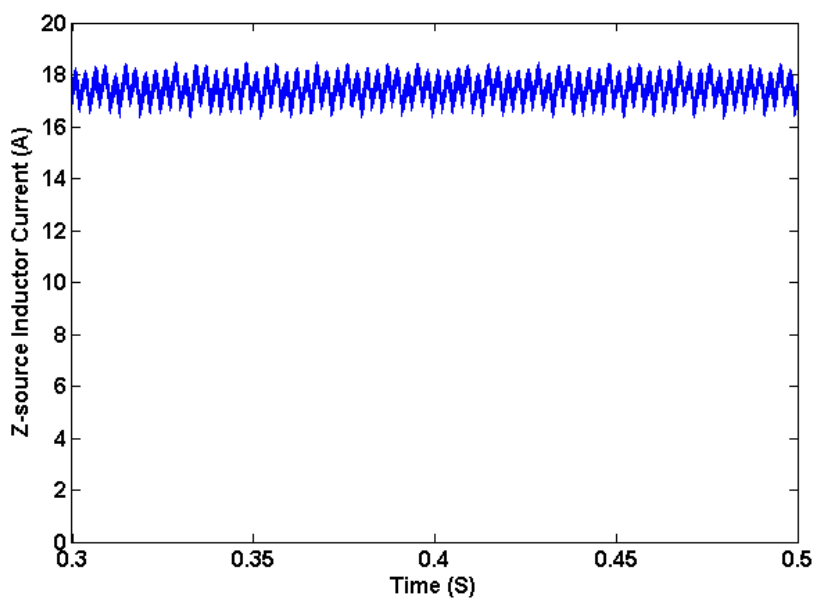

Fig. 22. Z-source inductor current of CTZS-NSI based on front-end rectifier ( $L_{1}$ current in Fig. 9).

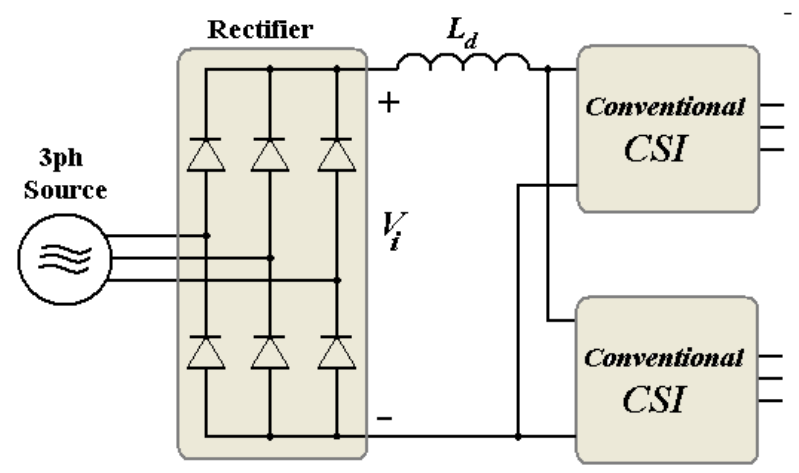

Fig. 23. Conventional CSIs to control two loads.

Semiconductor losses of the inverter include the switching loss and conduction loss. The conduction loss of a conventional CSI can be expressed by [14]:

$$
L_{\text {Loss-Con }}=2\left(V_{c e} I_{i}+r_{C E} I_{i}^{2}+V_{f} I_{i}+r_{f} I_{i}^{2}\right) \text {. }
$$

In the case of a CS-NSI, since three switches are always 
$\mathrm{ON}$, the conduction loss of can be expressed by:

$$
P_{\text {Loss-Con }}=3\left(V_{c e} I_{i}+r_{C E} I_{i}^{2}+V_{f} I_{i}+r_{f} I_{i}^{2}\right) .
$$

The switching loss of a conventional CSI can be expressed by [14]:

$$
P_{\text {Loss }-S W}=f_{s} \frac{3}{\pi}\left(E_{O N}+E_{O F F}+E_{r r}\right) \frac{I_{i}}{I_{n}} \frac{v_{\text {line }}}{V_{n}}
$$

where, $f_{s}$ is the switching frequency, $I_{i}$ is the current of the DC link and $v_{\text {line }}$ is the peak line voltage of the output. $E_{O N}$, $E_{O F F}$ and $E_{r r}$ are the wasted energies for turning a switch ON, turning a switch OFF and turning a diode OFF in the current $I_{n}$ and the voltage $V_{n}$ that can be obtained from the datasheet.

The switching loss of the CS-NSI depends on the frequency and phase of the outputs because the voltage stress of the middle switches is related to the difference between the line voltages of the two outputs. Minimum loss occurs when both outputs have the same frequency, phase and amplitude (in this case the voltage stress of the middles switches is zero):

$$
P_{\text {Loss }-S W}=f_{s} \frac{6}{\pi}\left(E_{O N}+E_{O F F}+E_{r r}\right) \frac{I_{i}}{I_{n}} \frac{v_{\text {line }}}{V_{n}} .
$$

Maximum loss occurs when both outputs have the same frequency and amplitude but with a phase difference of 180 degrees:

$$
P_{\text {Loss }-S W}=f_{s} \frac{12}{\pi}\left(E_{O N}+E_{O F F}+E_{r r}\right) \frac{I_{i}}{I_{n}} \frac{v_{\text {line }}}{V_{n}} .
$$

As an example, two conventional systems and the proposed system have been designed for two $6 \mathrm{~kW}$ loads with a peak line voltage of $1000 \mathrm{~V}$. Table $\mathrm{V}$ shows the designed systems. It can be seen that the efficiency is reduced in the proposed system by between 0.9 and 1.6 percent.

TABLE V

Proposed And Conventional System Designed For EFficiency COMPARISON

\begin{tabular}{|l|l|l|}
\hline Parameter & Conventional System & Proposed System \\
\hline$v_{\text {line-grid }}$ & $380 \mathrm{~V}$ (RMS) & $380 \mathrm{~V}$ (RMS) \\
\hline$v_{\text {line-output }}$ & $1000 \mathrm{~V}$ (peak) & $1000 \mathrm{~V}$ (peak) \\
\hline Load & $2 * 6 \mathrm{~kW}$ & $2 * 6 \mathrm{~kW}$ \\
\hline fs & $6.3 \mathrm{kHz}$ & $6.3 \mathrm{kHz}$ \\
\hline \multirow{3}{*}{ Rectifier } & $\begin{array}{l}\text { Semikron-SK55D08 } \\
800 \mathrm{~V}-45 \mathrm{~A}\end{array}$ & $\begin{array}{l}\text { Semikron-SK55D08 } \\
800 \mathrm{~V}-45 \mathrm{~A}\end{array}$ \\
\cline { 2 - 3 } & Ploss $=60 \mathrm{~W}$ & Ploss $=60 \mathrm{~W}$ \\
\hline \multirow{2}{*}{$L_{d}$} & $20 \mathrm{mH}$ & $20 \mathrm{mH}$ \\
\cline { 2 - 3 } & Ploss $=120 \mathrm{~W}$ & Ploss $=120 \mathrm{~W}$ \\
\hline \multirow{3}{*}{ GBT } & $\begin{array}{l}\text { IXYS-IXRP 15N120 } \\
\text { IXY }\end{array}$ & $\begin{array}{l}\text { IXY }-\mathrm{IXRH} 40 \mathrm{~N} 120 \\
1200 \mathrm{~V}-35 \mathrm{~A}\end{array}$ \\
\cline { 2 - 3 } & Ploss $=2 * 84 \mathrm{~W}$ & Ploss $=275-370$ \\
\hline \multirow{2}{*}{ Efficiency } & $97.1 \%$ & $95.42 \%-96.21 \%$ \\
\hline
\end{tabular}

\section{CONCLUSIONS}

This paper has presented two dual-output current source inverters, called a current source nine-switch inverter (CS-NSI) and a current-type z-source nine-switch inverter (CTZS-NSI). These inverters are composed of only nine semiconductor switches. Both inverters can control two ac loads independently. The current-type z-source nine-switch inverter can also boost the input DC current. While a conventional CSI with a diode front-end rectifier acts as a voltage boost converter, one of the outputs of the CS-NSI and both outputs of the CTZSNSI can act as voltage buck converter in addition to their voltage boost capacity. A SVM method was presented for the proposed inverters. Simulation results show the validity and performance of the proposed inverters and also the proposed space vector modulation methods.

\section{REFERENCES}

[1] B. Wu, J. Pontt, J. Rodríguez, S. Bernet, and S. Kouro, "Current-source converter and cycloconverter topologies for industrial medium-voltage drives," IEEE Transaction on Industrial Electronics, Vol. 55, No. 7, pp. 2786-2797, Jul. 2008.

[2] A. R. Beig, and V. T. Ranganathan, "A novel CSI-Fed induction motor drive," IEEE Transaction on Power Electronics, Vol. 21, No. 4, pp. 10731082, Jul. 2006.

[3] T. Kominami, and Y. Fujimoto, "A novel nine-switch inverter for independent control of two three-phase loads," IEEE Industry Applications Society Annual Conference (IAS), pp. 2346-2350, Sep. 2007.

[4] C. Liu , B.Wu, N. Zargari, and D. Xu: "A novel three-phase threeleg AC/AC converter using nine IGBTs," IEEE Transaction on Power Electronic, Vol. 24, No. 5, pp. 1151-1160, May 2009.

[5] C. Liu , B. Wu, N. Zargari, and D. Xu: "A novel nine-switch PWM rectifier-inverter topology for three-phase UPS applications," Journal of European Power Electronics (EPE), Vol. 19, No. 2, pp. 1 -10, Jun. 2009.

[6] V. Delli Colli, P. Cancelliere, F. Marignetti, and R. Di Stefano, "Voltage control of current source inverters," IEEE Transaction on Energy Conversion, Vol. 21, No. 2, pp. 451-458, Jun. 2006.

[7] L.A. C. Lopes, and M. F. Naguib, "Space vector modulation for low switching frequency current source converters with reduced low-order noncharacteristic harmonics," IEEE Transaction on Power Electronic, Vol. 24, No. 4, pp. 903-910, Apr. 2009.

[8] S.M. Dehghan, M. Mohamadian, A. Yazdian, and F. Ashrafzadeh, "A novel space vectors modulation for nine-switch converters," IEEE Energy Conversion Congress and Exposition (ECCE), pp. 885-591, Sep. 2009.

[9] F. Z. Peng, "Z-source inverter," IEEE Transactions on Industry Applications, Vol. 39, No. 2, pp. 504-510, Mar./Apr. 2003.

[10] X. P. Fang, Z. M. Qian, Q. Gao, B. Gu, F. Z. Peng and X. M. Yuan, "Current Mode Z-Source Inverter-Fed ASD System," in Pro. of IEEE Power Electronics Specialists Conference, Vol. 4, pp. 2805-2809, 2004.

[11] P. C. Loh, D. M. Vilathgamuwa, C. Gajanayake, L.T. Wong, and C. P. Ang, "Z-Source Current-Type Inverters: Digital Modulation and Logic Implementation," IEEE Transaction on Power Electronics, Vol. 22, No. 1, pp.169-177, Jan. 2007.

[12] P.C. Loh, C. J. Gajanayake, D. M. Vilathgamuwa and F. Blaabjerg, "Evaluation of Resonant Damping Techniques for Z-Source CurrentType Inverter," IEEE Transaction on Power Electronics, Vol. 23, No. 4 pp. 2035-2043, Jul. 2008.

[13] Robert E. Hill, Micrometals, Inductor Design Software 2009, http://www.micrometals.com/software_index.html.

[14] M. H. Bierhoff and F. W. Fuchs, "Semiconductor Losses in Voltage Source and Current Source IGBT Converters Based on Analytical Derivation," Power Electronics Specialists Conference (PESC), Aachen, 2004.

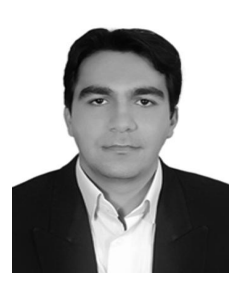

Seyed Mohammad Dehghan was born in Tehran, Iran, in 1981. He received his B.S. in Electrical Engineering from Azad Islamic University, Yazd, Iran, in 2003 and his M.S. in Electrical Engineering from Tarbiat Modares University, Tehran, Iran, in 2005. He is currently pursuing his Ph.D. at Tarbiat Modares University, Tehran, Iran. Since November 2009, he has been a visiting student at the Technical University of Denmark. His current research is on inverters, motor drives, inverter based DG, hybrid electric vehicles and FACTS. 


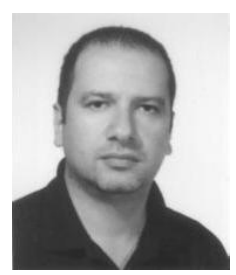

Mustafa Mohamadian received his B.S. in Electrical Engineering from the AmirKabir University of Technology, Tehran, Iran, in 1989, his M.S. in Electrical Engineering from Tehran University, Tehran, Iran, in 1992 and his Ph.D. in Electrical Engineering, specializing in power electronics and motor drives, from the University of Calgary, Calgary, Canada in 1997. Since 2005, he has been with Tarbiat Modares University, Tehran, Iran, as an Assistant Professor in the Department of Electrical and Computer Engineering. Dr. Mohamadian' main research interests include modeling, analysis, design, and control of power electronic converters/systems and motor drives. His area of interest also includes embedded software development for automation, motion control and condition monitoring of industrial systems with microcontrollers and DSPs.

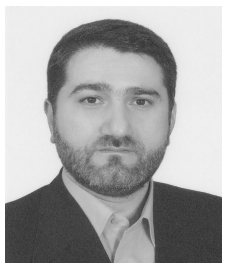

Ali Yazdian was born in Tehran, Iran. He received his B.Sc in Electrical Engineering from the Sharif University of Technology in 1989 and his M.Eng (Hons) and Ph.D. in Electrical Engineering from the University of Wollongong, Australia, in 1995 and 1999 respectively.

$\mathrm{He}$ is currently an Assistance Professor in the Electrical Engineering Department of Tarbiat Modares University. His research interests include FACTS, power quality, power system protection and information security. 